\title{
Flexural Performance of Concrete Beams Reinforced with Epoxy Resin/Glass and Carbon Fibers Composites
}

\author{
Tiago Teixeira da Silva Braga ${ }^{a}$, Nathan Pereira de Andrade ${ }^{a}$, Antônio Wanderley Terni ${ }^{a}$, \\ Daniel Cônsoli Silveira ${ }^{b}$ Edson Cocchieri Botelho ${ }^{b *}$ (D) \\ ${ }^{a}$ Universidade Estadual Paulista, Departamento de Engenharia Civil, Guaratinguetá, SP, Brasil. \\ ${ }^{b}$ Universidade Estadual Paulista, Departamento de Materiais e Tecnologia, Guaratinguetá, SP, Brasil.
}

Received: March 2, 2021; Revised: July 23, 2021; Accepted: August 12, 2021

\begin{abstract}
Factors such as project and execution errors, lack of maintenance and inspection, and increases in loading can cause deficiencies to reinforced concrete structures. In this regard, there is the necessity of the application of structural reinforcement systems. This manuscript aims at the structural capacity analyses involving the bending of steel-reinforced concrete beams with additional reinforcement of polymer composites using glass and carbon fibers, and its comparison with regular reinforced concrete beams. Steel-reinforced concrete, polymeric composite, and hybrid beams (steel-reinforced concrete and polymeric composite combined) were submitted to the four-points bending test. Experimental and calculated results for the dimensioning of the beams were compared, allowing the validation of the calculation method and its implementation. It was possible to notice both the efficiency of the composite material applied as reinforcement, as well as the efficiency of the calculation models applied in this work.
\end{abstract}

Keywords: Polymer composite, steel reinforced concrete, structural reinforcement, glass fiber/ epoxy laminate, carbon fiber/epoxy laminate.

\section{Introduction}

Each structure changes over time with a limited useful life, for that matter, every structural element will deteriorate over the years of service, either for internal or external reasons ${ }^{1}$. Engineering studies related to pathologies, their origins, and their consequences aim at a common goal: the guarantee of satisfactory performance of structures, i.e. the behavior in service of each product, result of each one of the steps of the design and execution, considering key factors, such as degradation of the structure, by physical or chemical attack, the use and intended useful life of the structure ${ }^{2}$.

An important concept, still in the general understanding of pathologies, is that a failure committed in the process of designing the structure makes the solution to the problem much more complex. These types of errors are much more difficult to be solved in the future, when compared to those who had an erroneous execution or a failure in the maintenance of the structure, since the first generates errors in an integral way in the structure, and the second generates localized pathologies ${ }^{3-5}$.

After the emergence of pathology in the structure, consequently, arises the necessity for its recovery through a technical intervention, which can be defined as a series of procedures to stabilize a process of structural degradation, reverse the situation, and modify the performance of the element in question ${ }^{6,7}$. The repair in structural elements occurs due mainly to degradation of the concrete or the steel used as

*e-mail: edson.cocchieri.botelho@gmail.com reinforcement, which may be shallow or superficial, semideep or deep, according to the penetration of the damage $\mathrm{e}^{8,9}$.

Usually, the structural reinforcements used are based on the techniques of increasing the reinforced concrete section, such as reinforcement with a new reinforced concrete layer ${ }^{10}$ which is a common technique using consolidated and easily accessible materials but with architectural interference and the need for close attention to the adhesion between the layers, reinforcement with a new layer of reinforced concrete with the addition of fibers ${ }^{11}$ which brings great tensile strength in addition to the previous technique, but at a higher cost, reinforcements with metal profiles ${ }^{12}$, used in emergency interventions with fast execution, but recurring maintenance and architectural interference, or reinforcements with metal sheets, through bonding with polymer resins ${ }^{13}$ or anchored with screws, wires, or metal angles ${ }^{14}$ which also have fast execution, with little noise and architectural interference, but obstructing the view of new cracks.

New solutions consolidated in the market involve the use of fiber-reinforced polymers (FRP), such as carbon, polyaramid, and glass fibers, resulting in high rigidity and mechanical strength, and taking advantage of the low specific mass, the main feature of polymer composites ${ }^{15-18}$. The reinforcement can be performed in different ways, such as bending and shear mode reinforcement, by confinement, and in structural masonry, wood, and metal ${ }^{19,20}$.

In recent years, a lot of research has been carried out in the field of fiber-reinforced polymers (FRP) being used as 
reinforcement in civil structures due to the large number of combinations of polymeric matrices and fibers that can be studied $^{21,22}$. Thus, this sector continually advances creating and characterizing new materials and studying their application in the civil construction sector.

Schober et al. ${ }^{23}$ studied the reinforcement of wooden structures with FRP material through adhesives. A review of the latest in the sector was carried out, citing glass, carbon, aramid, and basalt fibers, as well as different types of adhesives such as polyurethanes, polyesters, phenolics, and amino plastics, with special emphasis on epoxy-based adhesives. The authors also present a design model considering fractures and delamination, and the main proposed applications are reinforcement at the end of beams, improvement in tensile strength, shear reinforcement, and FRP prestressing acting on the tensile component of a bending beam.

Qin et al. ${ }^{24}$ evaluate the effect of the reinforcement ratio on the structural performance of hybrid beams, reinforced by FRP and steel. Nonlinear 3D finite element models are proposed to simulate beams reinforced by the hybrid system. The study of the ratio between the FRP and steel reinforcements allows us to determine the ideal range of values that promotes the post-elastic strength of the beam with sufficient ductility and rigidity. Finally, the advantages of over-reinforcement models, high structural performance, and under-reinforced, economical, are demonstrated.

Zhu et al. ${ }^{25}$ investigated the bending structural behavior of high-strength partially reinforced concrete beams reinforced with basalt FRP bars using 4-point bending tests. A model for calculating the moment of inertia was developed to determine the deflection of the service load on the beams. It was also observed the influence of the variation in the ratio between steel and FRP reinforcement, such as flexural capacity, ductility, deflection, and cracks.

Gómez et al. ${ }^{26}$ studied the behavior of wooden beams reinforced by different types of FRP and metallic fibers when subjected to bending. Adhesion was performed using epoxy resins and reinforcements were prepared with carbon fiber, high modulus of elasticity carbon fiber, glass fiber, basalt fiber, and metallic fibers. Different configurations were tested and compared with the unreinforced beam. It was determined that the fibers substantially increased the initial strength of the beams, especially fibers with a lower modulus of elasticity, such as basalt and glass.

Thus, this manuscript aims to analyze the structural capacity gain in bending of concrete beams reinforced with composite plates using glass and carbon fiber composite laminates. This study focuses on the use of fiber-reinforced polymer composites (FRP) in civil engineering and its comparison with reinforced concrete beams, validating structural gains and calculation methodology.

\section{Experimental}

\subsection{Materials and methods}

The reinforced concrete beams were prepared according to the recipe $1: 2.23: 2.99: 0.56$, with the application of plasticizing additive, in the proportion of $1.5 \% \mathrm{~m} / \mathrm{m}$ of cement, to improve the densification of the concrete.
The cement used in this study was the type CPII-32, with a small aggregate with a maximum diameter of $2.4 \mathrm{~mm}$, large aggregate with dimensions between 4.8 , and $9.5 \mathrm{~mm}$ and the plasticizing additive Fazgrauth, from Vedacit Company.

The steel reinforcement of the concrete beams was prepared with $5 \mathrm{~mm}$ diameter CA-60 steel, with single-bar longitudinal reinforcement and single-branch transversal reinforcement to undersize the structure and ensure distribution of stress in the composite reinforcement, evaluating structural gain due to the application of glass fiber/epoxy (FRP-G) and carbon fiber/epoxy laminates (FRP-C). The steel reinforcements were integrated through welding with a coated electrode to ensure the proper union and positioning inside the mold.

The polymeric structural composites were laminated using epoxy resin pre-impregnated fiber fabric, with a curing cycle at $127 \pm 6^{\circ} \mathrm{C}$, a tensile strength of $80 \mathrm{MPa}$, and an elastic modulus of $3.24 \mathrm{GPa}$. The glass fiber fabric used was a plain weave style, with a weight of $115 \mathrm{~g} / \mathrm{m}^{2}, 38 \%$ in fiber volume, a tensile strength of $393 \mathrm{MPa}$, a tensile modulus of $20.7 \mathrm{GPa}$, a compression strength of $444 \mathrm{MPa}$, and a compression modulus of $20.7 \mathrm{GPa}$. The carbon fiber fabric used was also a plain weave style, with a weight of $194 \mathrm{~g} / \mathrm{m}^{2}$, $50 \%$ in fiber volume, a tensile strength of $848 \mathrm{MPa}$, a tensile modulus of $58 \mathrm{GPa}$, a compression strength of $904 \mathrm{MPa}$, and a compression modulus of $57.2 \mathrm{GPa}$. All the properties present at room temperature of $24{ }^{\circ} \mathrm{C}^{27}$.

\subsection{Design of concrete beams and composite}

The design of concrete beams is performed according to NBR 6118:2014 ${ }^{28}$ and presents as a hypothesis a rectangular section beam subject to bending moment, to determine the steel necessary to withstand the tensile load originated in the specimen. The design considers the strength of the prepared concrete, the steel used, and the bending moment in question ${ }^{29}$. Using Equations 1, 2, 3, and 4 is possible to obtain the calculation coefficients $\left(K_{C}, K_{S}\right.$, and $\left.K_{X}\right)$ and the steel area of the concrete reinforcement $\left(A_{S}\right)$, as follows:

$$
\begin{gathered}
K_{C}=\frac{M_{d}}{b_{w} * d^{2} * f_{c d}} \\
K_{X}=1,25 * \sqrt{1,5625-3,6765 * K_{C}} \\
K_{S}=\frac{1}{1-0,4 * K_{X}} \\
A_{S}=\frac{K_{S} * M_{d}}{d^{*} f_{y d}}
\end{gathered}
$$

Considering $M_{d}=$ calculated bending moment; $b_{w}=$ nominal width of the specimen cross-section; $d=$ distance from the reinforcement center of gravity to the most compressed fiber of the concrete; $f_{c d}=$ calculated compressive strength of concrete; and $f_{y d}=$ calculated compressive strength of steel.

The design is performed according to the desired behavior on the beam concerning the deformation of the concrete and steel. It is called a normally reinforced beam when the concrete has already reached the rupture specific yield strength (3.5\%o) and the steel is exactly in the specific 
yield strength (2.5\%o for CA-60 steel), this point is the boundary between domains 3 and 4 , and according to the type of steel used, corresponds to a $K_{X}$ of 0.59 . It is called sub-reinforced beam on two occasions: when the steel has already completely yielded before reaching the rupture specific deformation of the concrete, corresponding to a $K_{X}$ less than 0.26 (Domain 2); and when the steel has not yet reached the specific yield strength when the concrete reaches the rupture specific yield strength, corresponding to a $K_{X}$ interval between 0.26 and 0.59 (Domain 3). Finally, it is called a super-reinforced beam when the concrete has already reached the rupture specific yield strength and the steel has not yielded yet, corresponding to a $K_{X}$ higher than 0.59 . A visual demonstration of the domains, according to the rupture specific yield strength of the concrete $\left(\varepsilon_{\mathrm{cu}}\right)$ and specific yield strength of the steel $\left(\varepsilon_{\mathrm{yd}}\right)$, can be seen in Figure 1.

The design of the polymer composite was performed with the assistance of a manual based on normative considerations such as ACI 440.2R-17 and ACI 318-1930,31. The sizing is iterative and based on the dimensions of the cross-section, steel area, and mechanical properties of the element being reinforced. The bending moment $\left(M_{d}\right)$ calculation is based especially on the Equation 5, considering " $A_{s}$ " as steel reinforcement area; " $y$ " as the height of the concrete simplified rectangular diagram; " $\Psi_{R}$ " as a reduction factor, " $A_{R}$ " as composite reinforcement area; " $f_{R}$ " as reinforcement strength; and " $\mathrm{d}_{\mathrm{R}}$ " as the distance from the reinforcement center of gravity to the most compressed concrete fiber.

$$
M_{d}=A_{s} * f_{y d} *\left(d-\frac{y}{2}\right)+\Psi_{R} * A_{R} * f_{R} *\left(d_{R}-\frac{y}{2}\right)
$$

\subsection{Processing of concrete beams}

The preparation of the concrete specimens was performed with the mechanical mixing of binder, aggregates, additives, and water, gradually and orderly. Wooden molds were used to ensure the shape of the beam and avoid eccentricities in the specimen, in addition to ensuring the proper positioning of the reinforcement, according to Figure 2. Additionally, 4 cylindrical specimens were prepared with $10 \mathrm{~cm}$ in diameter by $20 \mathrm{~cm}$ in height, for compression tests and determination of the concrete compression strength $\left(f_{c k}\right)$, according to NBR 5739:2007 $7^{32}$. After three days in the molds, the samples were, including the cylindrical ones, unmold and left in the process of curing in a tank with water for 23 days at room temperature.

\subsection{Composite processing}

The composite manufacturing is based on the hand layup of 15 layers of pre-impregnated material with $0 / 90^{\circ}$ orientation, with $30 \mathrm{~cm}$ x $30 \mathrm{~cm}$ dimension according to the mold used in the hot compression molding process. The surfaces of the mold were prepared with the release agent Polidesmo 55 to facilitate the removal of the polymer composite.

The curing cycle of the material was determined by differential scanning calorimetry (DSC) according to ASTM E2041-13 ${ }^{33}$ and thermogravimetric analyses (TGA) according to ASTM E2550-11 ${ }^{34}$. Twenty-four scans were performed in dynamic mode, according to the experimental planning matrix with $2^{3}$ full factorial design, obtaining 96 temperatures distributed among curing and thermal degradation phenomena of the material.

The hot compression molding process was performed in a CMV100H-15-X hydraulic press with constant pressure of $0.61 \pm 0.03 \mathrm{MPa}$, according to the curing cycle presented in Figure 3. Figure 4 presents the FRP plates obtained with $3 \mathrm{~mm}$ of final thickness and dimension markings for cutting process in a band saw, and subsequent milling and finishing of each FRP beam in a DMU 50 ECO cutter to avoid stress concentration that could depreciate the flexural strength ${ }^{35,36}$. The final plates had the dimensions of $6 \mathrm{~cm} \times 23 \mathrm{~cm}$, with $3 \mathrm{~mm}$ thickness.

The plates obtained were analyzed by an ultrasound test, to verify the adhesion and the processing quality of the preimpregnated layers during the molding process. The equipment used was the PSS-600 model of MATEC Instruments, with a frequency transducer of $2.25 \mathrm{MHz}$, and the OmniScan MX of Olympus, with a frequency transducer of $10 \mathrm{MHz}$, using the A-Scan and C-Scan methods, in both equipment.

\subsection{Preparation of the interface between concrete and composite}

Considered as the critical point in the application of the composite as reinforcement, the preparation of the interface

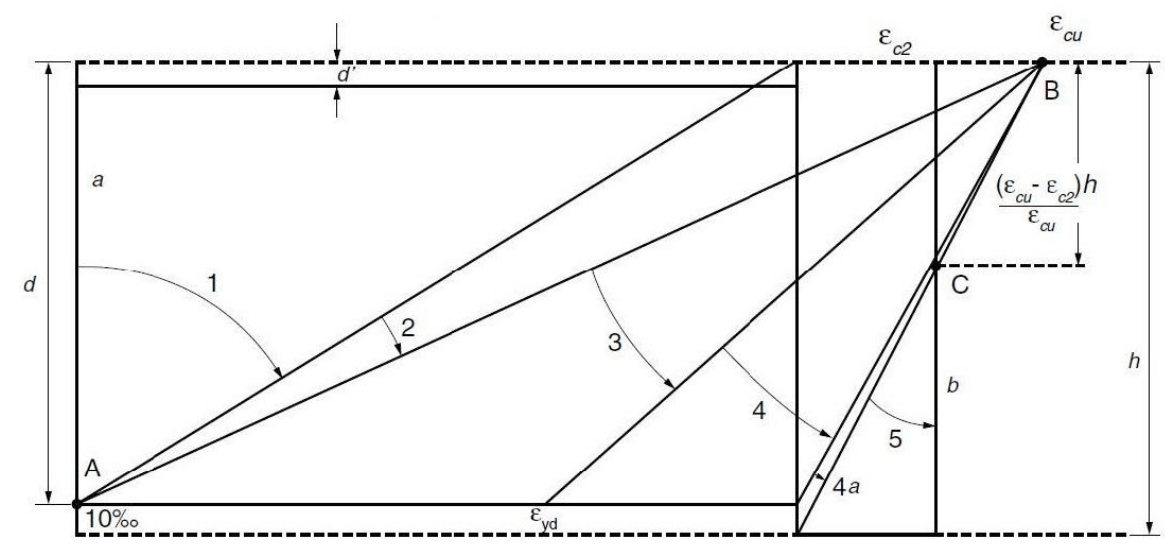

Figure 1. Domains of limit-state ${ }^{28}$. 
a)

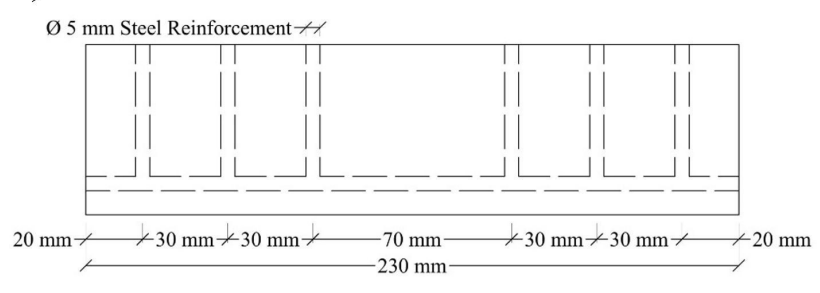

Side View

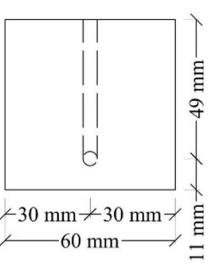

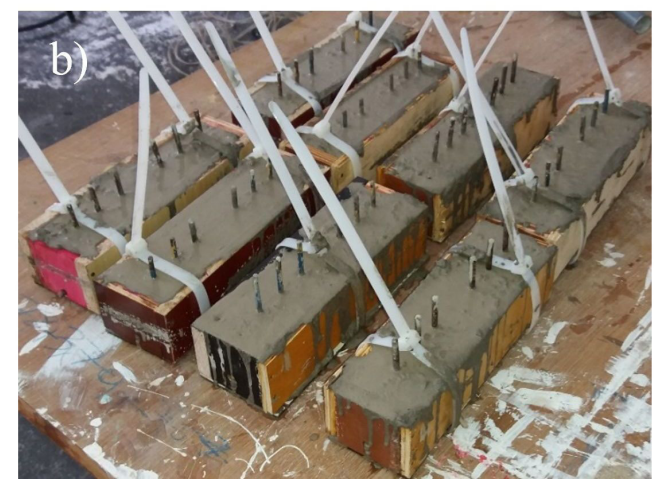

Figure 2. a) Dimensions and b) Production of concrete beams.

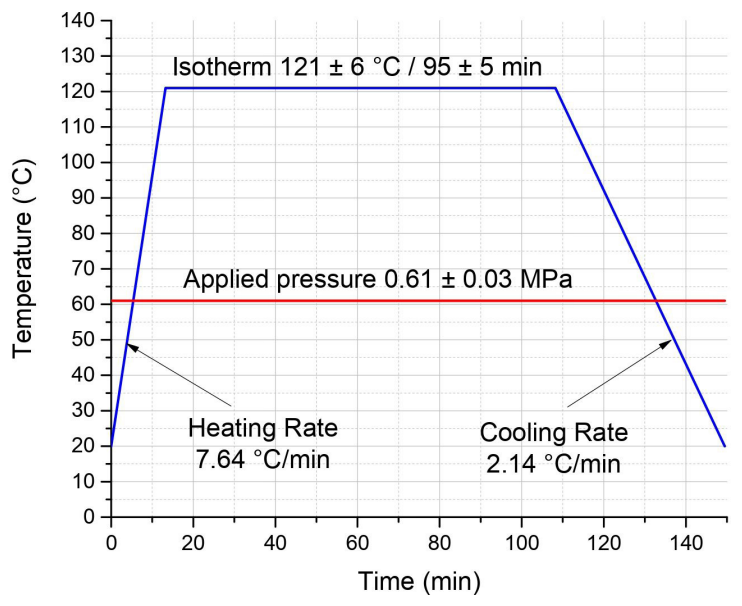

Figure 3. Curing cycle of epoxy resin laminates.

represents an especially important issue, to ensure the adhesion between the composite and the ceramic substrate of reinforced concrete ci,38. $^{37}$.

The preparation begins with the sanding of the concrete surface, followed by cleaning by compressed air. Then the application of the Viapol Carbon Primer, which, by penetrating via capillarity in the interstices of the concrete, improves the adhesive capacity of the surface, as represented in Figure 5a. The application of the structural adhesive is performed in sequence, approximately 2 hours after the primer, at the time it presents tack behavior. The structural adhesive used was Sikadur 31, with a layer of 1.5 to $2.5 \mathrm{~mm}$ thickness, as shown in Figure 5b. It is important to note that the structural adhesive has a high viscosity and base material similar to the FRP composite, epoxy resin. The composite plate is then positioned with pressure to ensure a homogeneous bonding and thickness along the entire element, as can be seen in Figure $5 \mathrm{c}$. The cure was performed in air at room temperature for 5 (five) days.

\subsection{Four-point bending test}

The four-point bending test was performed on the specimens, considering 3 (three) categories: reinforced concrete; polymer composite plate; and reinforced concrete with composite reinforcement (hybrid beam). The test was performed according to NBR 12142:2010 ${ }^{39}$, which is based on a bi-supported beam with two concentrated and symmetrical loads according to Figure 6, exemplifying the hybrid beam test but used for all specimens, including the FRP.

For the bending test was used an AG-X Universal Test Machine of Shimadzu, with a load cell of $50 \mathrm{kN}$ and the stop point of the tests defined in the rupture of the specimens, obtained with the assistance of an integrated software analyzing the data, without any strain or crack gauges and LVDT displacement. The test speed of $0.5 \mathrm{~mm} / \mathrm{min}$ was used for concrete and hybrid specimens (reinforced concrete and FRP) and $5 \mathrm{~mm} / \mathrm{min}$ for the FRP specimens.

\section{Results and Discussion}

\subsection{Ultrasound Inspection}

After the hot compression molding process, accomplished according to the defined curing cycle, the polymer composite was analyzed by ultrasound inspection, to determine the quality of the laminates, verifying the presence and distribution of defects. Figure 7 shows the obtained results.

In the ultrasound results, the clearer the image, the greater the return of the mechanical waves, so the white colored regions represent polymeric material reinforced with fibers with 100\% of wave attenuation. This result indicates homogeneity and 

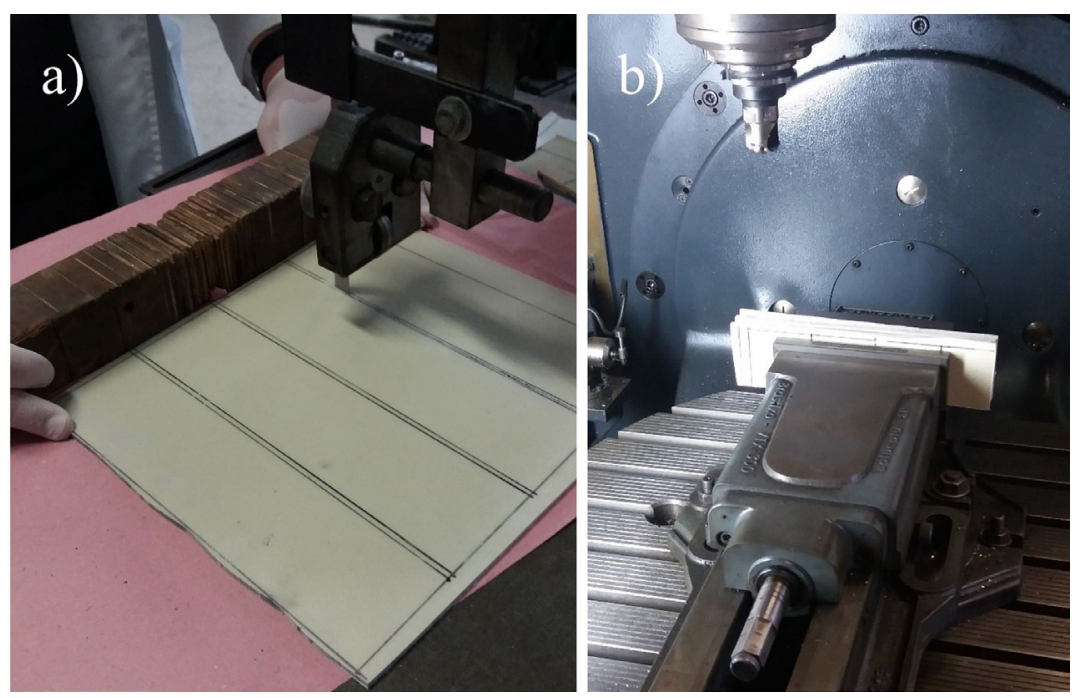

Figure 4. a) Cutting and b) Milling.
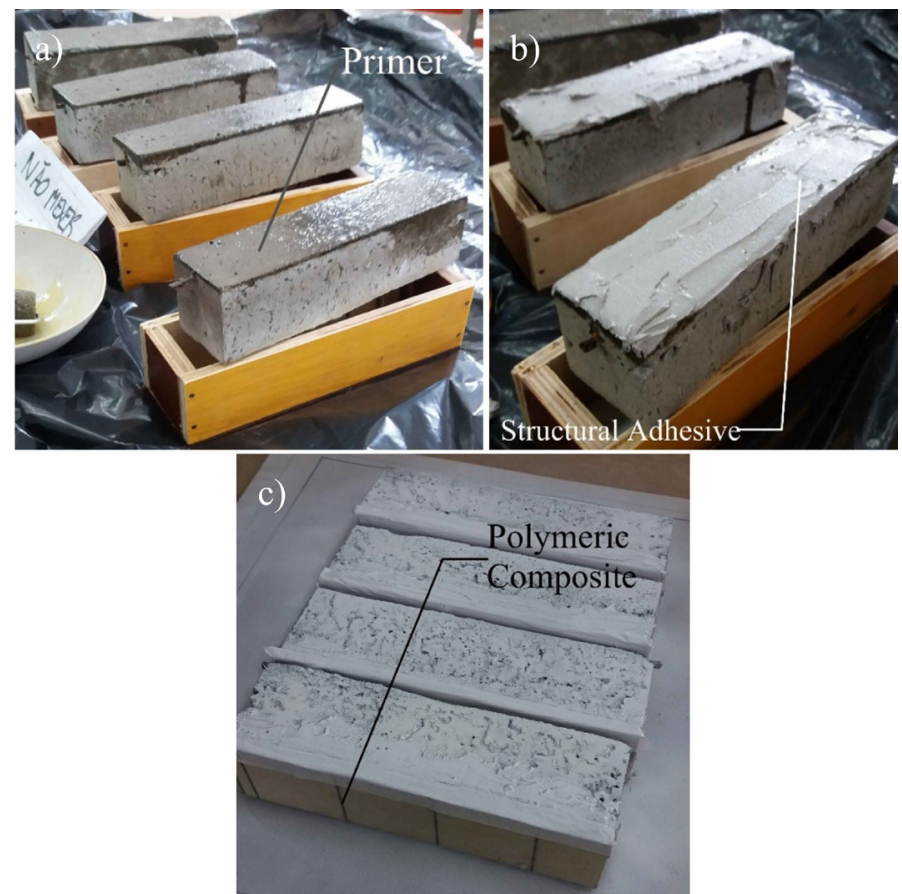

Figure 5. Interface between concrete and polymer composite: a) primer application; b) structural adhesive application; and c) final interface result.

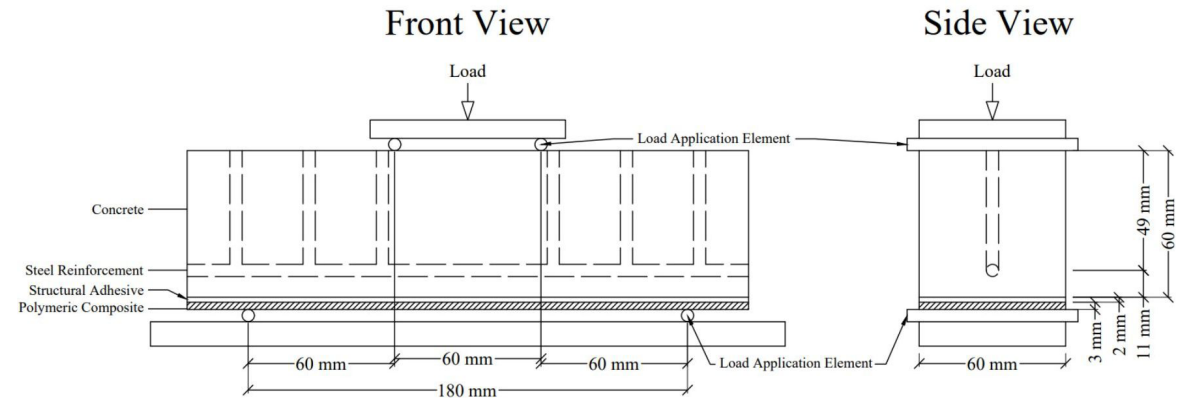

Figure 6. Conditions of the bending test on hybrid beams. 

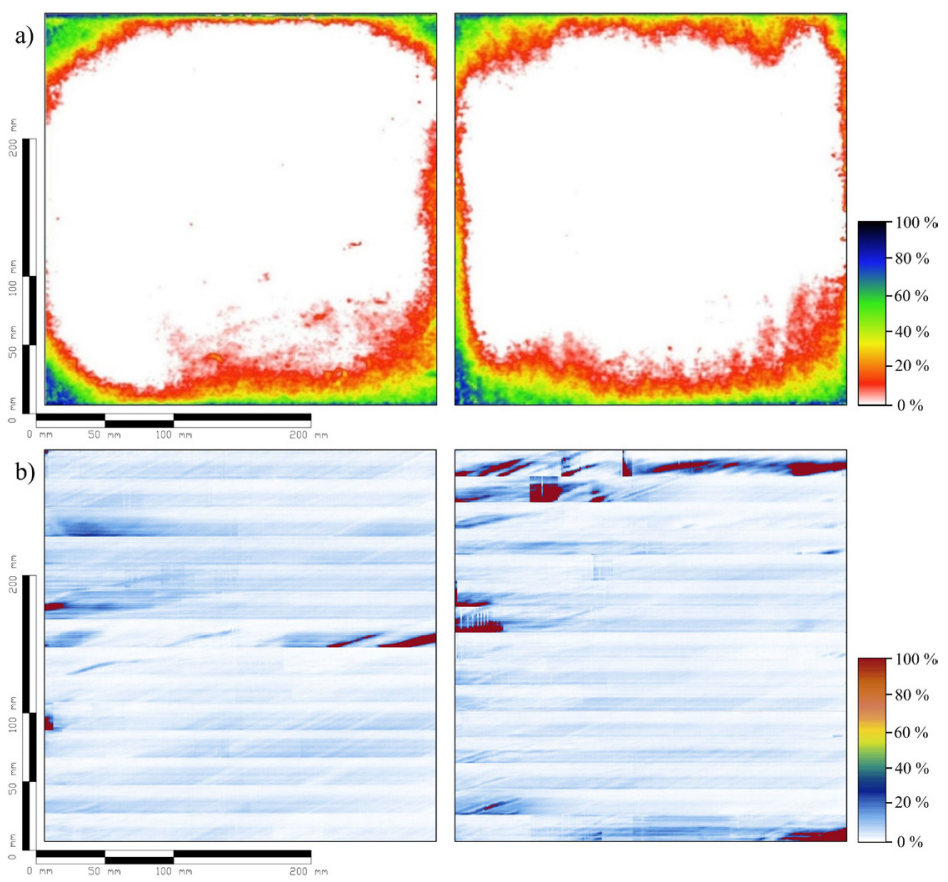

Figure 7. Ultrasound evaluation of the polymer laminates: a) FRP-G; b) FRP-C.

low presence of defects in the plates. However, it shows the edges have darker colors, indicating lesser attenuation at the ends of the FRP plates, which reduces structural performance. Based on the ultrasound results and for better structural performance, they were removed by cutting $2.5 \mathrm{~cm}$ from the edges of all glass and carbon fibers/epoxy resin composite plates, maintaining only regions of greater consolidation.

\subsection{Design of concrete and composite beams}

The designing of reinforced concrete beams was performed by the determination of the steel reinforcement used in the beams, with the adoption of a $\mathrm{K}_{\mathrm{X}}$ coefficient of 0.422 , the exact midpoint of domain 3 , between 0.259 and 0.585 . Thus, with Equations 3 and 4, the bending moment supported by the reinforcement, of $41.72 \mathrm{kN} . \mathrm{cm}$, is determined. All parameters can be observed in Table 1.

Performing the inverse process with Equations 1 and 2 , the minimum compressive strength of concrete $\left(f_{c k}\right)$ is determined so that it does not rupture before the reinforcement, the value obtained was $10.31 \mathrm{MPa}$, below the values obtained experimentally, through compression tests of cylindrical specimens according to NBR 5739:2007², of $18.00 \mathrm{MPa}$ and $17.57 \mathrm{MPa}$ in the first and second stages, respectively.

With the manipulation of the units, using the dimensions of the element, the testing parameters, support conditions, and the momentum reduction coefficient, represented by Equation 6, the maximum load $\left(F_{k, \max }\right)$ supported by the beam is obtained, $9.93 \mathrm{kN}$.

$$
F_{k, \text { max }}=\frac{M_{d} * 3 * 2}{1,4 * l}
$$

The design of the composite is usually performed iteratively, but, as the dimensions of the composite were
Table 1. Parameters obtained and used in the design.

\begin{tabular}{cc}
\hline \multicolumn{2}{c}{ Design Parameters } \\
\hline$M_{d}$ & $41.72 \mathrm{kN} . \mathrm{cm}$ \\
\hline$b_{w}$ & $6 \mathrm{~cm}$ \\
\hline $\mathrm{h}$ & $6 \mathrm{~cm}$ \\
\hline $\mathrm{d}$ & $1.03 \mathrm{kN} / \mathrm{cm}^{2}$ \\
\hline$f_{c k(\text { minimum })}$ & $0.74 \mathrm{kN} / \mathrm{cm}^{2}$ \\
\hline$f_{c d}($ minimum $)$ & $60.00 \mathrm{kN} / \mathrm{cm}^{2}$ \\
\hline$f_{y k}$ & $52.17 \mathrm{kN} / \mathrm{cm}^{2}$ \\
\hline$f_{y d}$ & 0.394 \\
\hline$K_{C}$ & 0.422 \\
\hline$K_{X}$ & 1.203 \\
\hline$K_{S}$ & $0.196 \mathrm{~cm}{ }^{2}$ \\
\hline$A_{S}$ & $0.500 \mathrm{~cm}$ \\
\hline$\varphi_{S}$ & \\
\hline
\end{tabular}

fixed $\left(0.3 \mathrm{~cm}\right.$ high $x 6.0 \mathrm{~cm}$ wide, resulting in $\left.1.80 \mathrm{~cm}^{2}\right)$, the design was carried out inversely, obtaining the resistance for the hybrid beam from the strength of the composite and its area, with Equation 5, and the concrete and reinforcement strength data previously determined. According to the design, the beams reinforced with glass fiber composite obtained a bending moment of $72.34 \mathrm{kN} . \mathrm{cm}$, while the beams reinforced 
Table 2. Bending tests results.

\begin{tabular}{|c|c|c|c|c|}
\hline & Sample & Type & Ultimate load $(\mathrm{N})$ & Ultimate stress $\left(\mathrm{N} / \mathrm{mm}^{2}\right)$ \\
\hline \multirow{12}{*}{ 1st Stage } & 1 & \multirow{4}{*}{ Reinforced Concrete } & $8,854.23$ & 7.38 \\
\hline & 2 & & $9,705.85$ & 8.09 \\
\hline & 3 & & $10,683.70$ & 8.90 \\
\hline & 4 & & $9,585.14$ & 7.99 \\
\hline & 5 & \multirow{4}{*}{ FRP-G } & $1,685.83$ & 561.94 \\
\hline & 6 & & $2,204.52$ & 734.84 \\
\hline & 7 & & $2,035.32$ & 678.44 \\
\hline & 8 & & $2,556.11$ & 852.04 \\
\hline & 9 & \multirow{4}{*}{$\begin{array}{c}\text { Hybrid } \\
\text { RC + FRP-G }\end{array}$} & $17,111.70$ & 12.15 \\
\hline & 10 & & $23,424.40$ & 16.63 \\
\hline & 11 & & $20,606.90$ & 14.63 \\
\hline & 12 & & $22,971.80$ & 16.31 \\
\hline \multirow{11}{*}{ 2nd Stage } & 13 & \multirow{4}{*}{ Reinforced Concrete } & $11,185.70$ & 9.32 \\
\hline & 14 & & $11,191.80$ & 9.33 \\
\hline & 15 & & $10,389.20$ & 8.66 \\
\hline & 16 & & $12,306.30$ & 10.26 \\
\hline & 17 & \multirow{3}{*}{ FRP-C } & $10,481.00$ & $3,493.67$ \\
\hline & 18 & & $9,982.71$ & $3,327.57$ \\
\hline & 19 & & $12,195.50$ & $4,065.17$ \\
\hline & 20 & \multirow{4}{*}{$\begin{array}{c}\text { Hybrid } \\
\text { RC + FRP-C }\end{array}$} & $28,150.70$ & 19.99 \\
\hline & 21 & & $24,686.90$ & 17.53 \\
\hline & 22 & & $28,239.60$ & 20.05 \\
\hline & 23 & & $30,079.80$ & 21.36 \\
\hline
\end{tabular}

with carbon fiber composite obtained a bending moment of $87.13 \mathrm{kN} . \mathrm{cm}$.

With the same manipulation of the units of the beams without reinforcement given by Equation 6, the maximum load supported by the beams with glass and carbon fibers reinforcement were obtained, $17.22 \mathrm{kN}$ and $20.75 \mathrm{kN}$, respectively.

\subsection{Bending tests}

The bending tests were performed on a total of 23 specimens, divided into 2 stages: the first with 12 specimens and the second with 11 specimens, following the configuration presented in Table 2, and with their respective results. The stress $\left(\mathrm{N} / \mathrm{mm}^{2}\right)$ was calculated using Equation 7, according to NBR $12142^{39}$, while the strain was calculated directly by the testing machine based on sample dimensions and testing parameters.

$$
f c t M=\frac{F^{*} l}{b_{w} * h^{2}}
$$

It is important to clarify that the two stages of this study were performed on different occasions, with different environmental conditions, thus, to ensure the comparability between the results with and without the FRP, it was decided to produce new specimens of the reinforced concrete beams in the second stage. The analysis of the data obtained in the bending of the reinforced concrete specimens of the first stage of this study (Samples 1 to 4), associated with the results observed in Figure 8, it is possible to notice that all four values are quite close to the expected, $9.93 \mathrm{kN}$, which proves the efficiency of the design method.

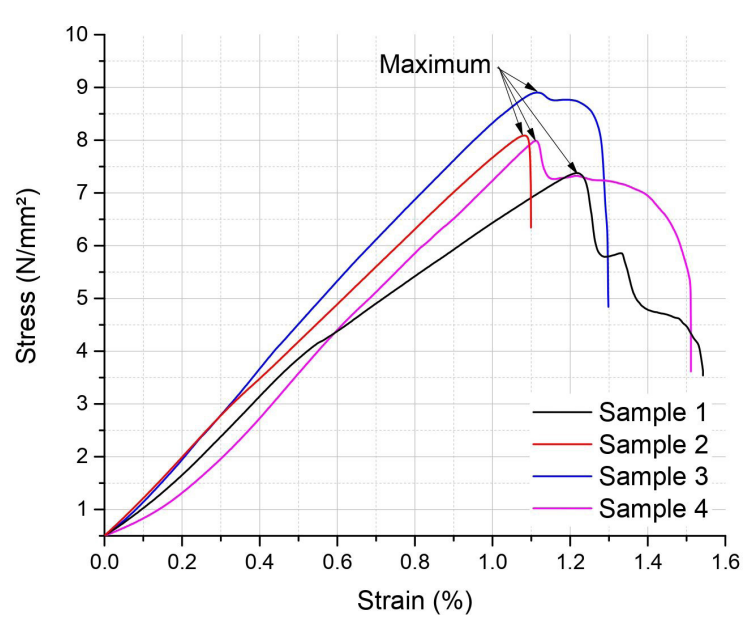

Figure 8. Flexure results of reinforced concrete beams (Samples 1 to 4$)$.

Analyzing the stress $\mathrm{x}$ strain diagrams for reinforced concrete beams without FRP-G (Figure 8), it is possible to observe an elastic behavior at the beginning of the tests. Specifically, for samples 1, 3 and 4, it is possible to observe a stress stabilization after the peak load is reached, which can be attributed to the steel deformation after the concrete rupture and before itself fails, which is clearer in the curve of sample 4 between 1.15 and $1.3 \%$.

The bending test on the FRP-G composite plates (Samples 5 to 8 ) provided the stress $\mathrm{x}$ strain diagrams shown in Figure 9. The analysis shows that the maximum stress values varied between 550 and $850 \mathrm{~N} / \mathrm{mm}^{2}$, with an 
average of $706.11 \mathrm{~N} / \mathrm{mm}^{2}$, and are within the range shown for different composites of glass fibers and epoxy resin ${ }^{40,41}$.

From the diagram (Figure 9), FRP-G beams 6 and 8 present, considering a strain of $2 \%$, approximately, a 750 and $850 \mathrm{~N} / \mathrm{mm}^{2}$ of maximum stress, respectively. The unusual format of the graph is attributed to the equipment used to transform a 3-point bending test into a 4-point. Due to its shape and the great deformation of the composite plate, at a certain point of the test, there is unexpected contact between them, interfering with load distribution and creating new stress points. It is possible to perceive slight stabilizations in the stress and a subsequent increase. These gains can be explained by a decrease in the resistant cross-section of the composite while each layer deforms, until the moment when the laminate generally fails. Abrupt and successive oscillations of falling and increasing stresses can be explained by the rupture of fiber monofilaments, with the stress being transferred sequentially and immediately to adjacent filaments ${ }^{42}$.

The flexure test in the hybrid beams (Samples 9 to 12), provided the stress $x$ strain diagrams of Figure 10.

Evaluating the ultimate load, it is possible to notice that only sample 9 presents a value close to the expected, of

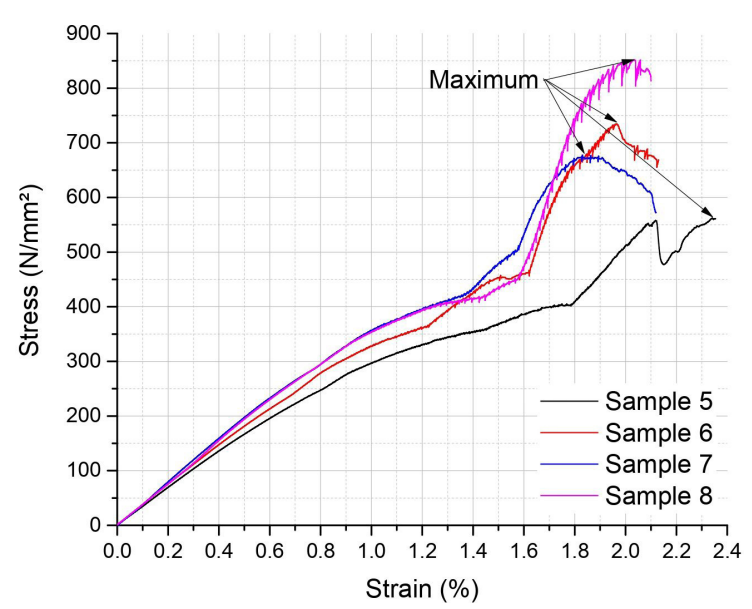

Figure 9. Flexure results of FRP-G laminates (Samples 5 to 8).

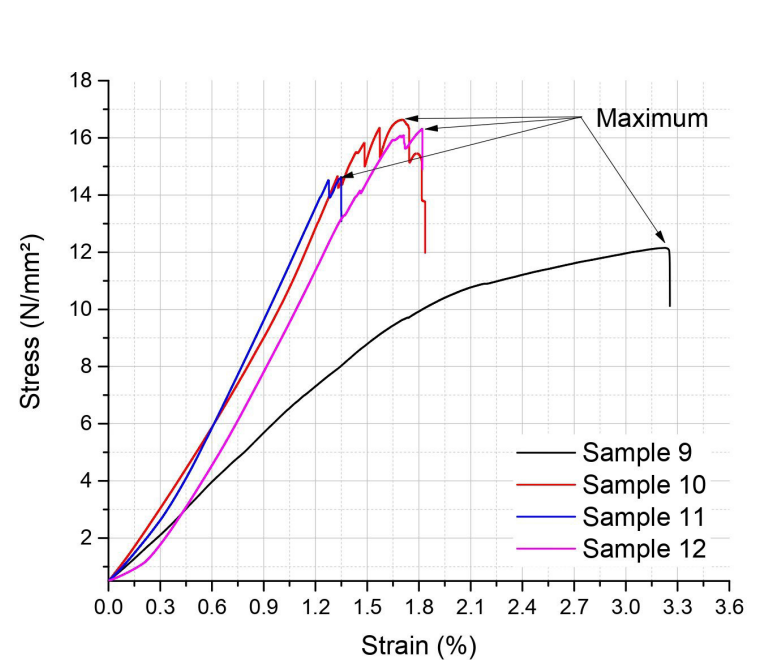

Figure 10. Flexure results of FRP-G hybrid beams (Samples 9 to 12).
$17.22 \mathrm{kN}$, but it also shows different behavior from the other specimens, along with a different type of rupture, indicating that the specimen failed due to compression. This situation can be attributed to errors during the preparation of this specific specimen. The other specimens presented higher values, which shows that the design method applied in this work, for the hybrid beams, is very conservative and values safety.

The bending test on reinforced concrete beams prepared in the second stage (Samples 13 to 16) provided the stress $\mathrm{x}$ strain diagrams shown in Figure 11. In general, all specimens presented values above expected, $9.93 \mathrm{kN}$, higher than that obtained in the first stage. This can occur due to several reasons, such as the quality of the raw material, adjustment of the concrete recipe to provide workability, and even curing and drying conditions, such as ambient temperature and air humidity.

The stress $\mathrm{x}$ strain diagrams show similar behavior with the reinforced concrete beams without FRP of the first stage, being elastic at the beginning of the test, with small oscillations due to the specimen being seated on the test machine. In specimens 15 and 16, it is possible to observe a slight plastic deformation before proceeding to the peak load supported.

Figure 12 shows the bending results on the FRP-C composite plates (Samples 17 to 19 ). The quantitative analysis of the maximum stress values indicates a range of variation between approximately 3,250 and 4,000 N/mm , with an average value of $3,628.80 \mathrm{~N} / \mathrm{mm}^{2}$.

Analyzing the diagram in Figure 12, it is noticeably clear the different behavior presented by the FRP-C beams. Firstly, the elastic behavior is noted up to a stress of approximately $1.1 \%$, with a stress between 500 and $750 \mathrm{~N} / \mathrm{mm}^{2}$, followed by a sharp increase in stress, featuring a plastic behavior, followed by the stabilizations observed in the FRP-G beams, and caused by the same reasons, just before reaching the maximum load.

Finally, the bending test on hybrid beams, reinforced concrete with the addition of FRP-C reinforcement (Samples 20 to 23), provided the stress x strain diagrams of Figure 13. Like the specimens 13 to 16 , all samples presented stress

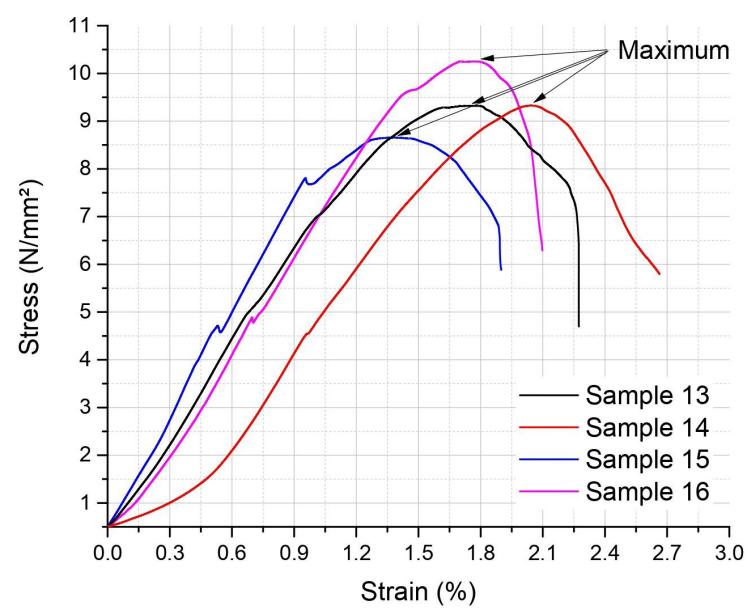

Figure 11. Flexure results of reinforced concrete beams (Samples 13 to 16$)$. 
values higher than expected, $20.75 \mathrm{kN}$, confirming that the calculation method used for hybrid beams values safety, and show an elastic behavior until reaching the maximum load.

\subsection{Cracking behavior}

Analyzing the cracking behavior of the specimens of the first stage, Figure 14 shows the fractures present in specimens 1 to 4 after the bending tests. Regarding the beams rupture, it is clear that all 4 beams have cracking starting in their lower region, close to the place where they were supported or even directly above the support point, with the crack spreading to the top of the beam.

Comparing with the fracture modes studied by Rocha et al. ${ }^{43}$, shown in Figure 15, it is observed that the fractures found are in regions $\mathrm{B}$ and $\mathrm{D}$, characterized by rupture due to the lack of sufficient transverse reinforcement to resist shear stresses and by lack of sufficient anchoring, respectively. In this second case, the beam breaks abruptly by sliding of the longitudinal reinforcement.

Figure 16 shows the fracture behavior after the bending tests in specimens 9 to 12 . The fractures of specimens 10 and 12 are visible and can also be classified as ruptures due to insufficient transverse reinforcement or sliding of the longitudinal reinforcement. However, it is possible to conclude that there was a detachment of the polymeric composite plate in its longitudinal ends, presented as horizontal cracks on the adhesive, due to the appearance of shear stress in the beams, a fact also related to the failure of the concrete by shear loading.

Specimen 9 does not show cracks clearly, it only shows a small flaw in the upper part of the beam, which indicates rupture by compression of the concrete. And specimen 11 shows a slight crack closer to the central region of the piece, characterizing a rupture in region A according to Figure 15. Rocha et al. ${ }^{43}$ explain that failures in region $\mathrm{A}$, with cracks in the lower region and close to the center, indicate a fragile and brittle failure mode, probable with yielding of the steel reinforcement.

Regarding the second stage, Figure 17 shows the ruptures present in the samples 13 to 16 after the bending tests. Again, it is very clear to notice that most specimens have fractures due to the lack of sufficient transverse reinforcement to resist the shear stress in the specimen (Sample 15), since its fracture on the lower part starts relatively distant from the support point, and due to lack of sufficient anchoring (Samples 14 and 16), with the fracture starting at the bottom, near the support, and being transmitted to the top. However, specimen 13 presented a different type of fissure, originating in the middle of the lower part and propagating to the upper part, in region $\mathrm{A}$, being characterized as a tensile rupture by pure flexion.

Figure 18 shows the crack propagation after the bending tests in samples 20 to 23 . The fracture in all specimens is visible, in region $\mathrm{D}$, and can also be classified as ruptures by sliding of the longitudinal reinforcement. It is possible to observe that there was also a detachment of the polymeric composite plate, with horizontal cracks between the support point and the tip of the beam.

\subsection{Comparisons of load capacities of beams with and without FRP reinforcement}

Regarding the data obtained in the first stage of the study, and calculating the average values, 9,707.2 $\mathrm{N}$ for specimens without composite reinforcement and 21,028.7 N with the FRP-G reinforcement, it is notable the increase in the load capacity of the beams reinforced with FRP system, the inclusion of the glass fiber/epoxy laminate increases the bending resistance by $116.63 \%$.

An interesting aspect to note is that with the insertion of the reinforcement, two of the four specimens showed a difference in the fracture mode compared to those without FRP-G reinforcement. For example, sample 11 visually showed a fragile and brittle failure with a possible yielding of the steel reinforcement, showing itself to be in domain 2 (sub-reinforced beam), in which the steel has already reached its yield stress and the concrete has not yet reached its maximum yield strength of $3.5 \%$. Sample 9 visually showed no cracks, which indicates the sudden collapse of the concrete, without warning, characterizing domain 4 (superreinforced beam), when the concrete is at its maximum yield strength of $3.5 \%$ and the steel has not yielded yet. This behavior indicates a clear increase in the capacity of

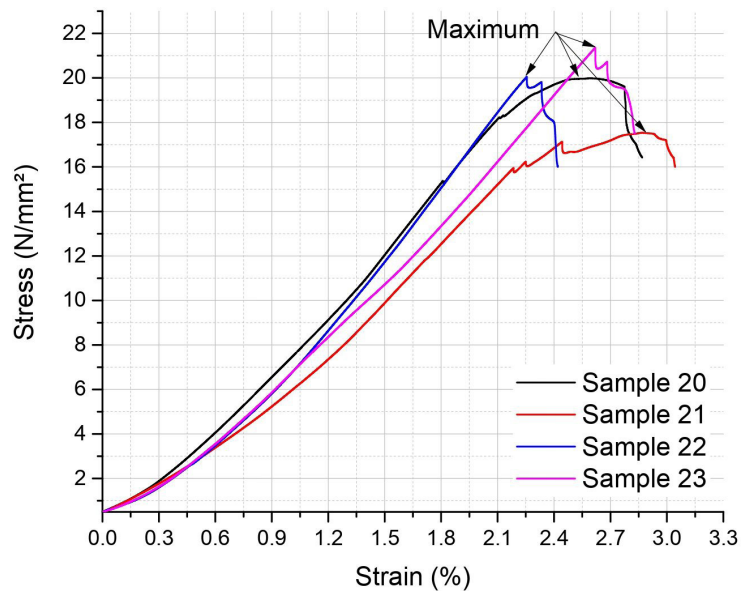

Figure 13. Flexure results of FRP-C hybrid beams (Samples 20 to 23).
Figure 12. Flexure results of FRP-C laminates (Samples 17 to 19).

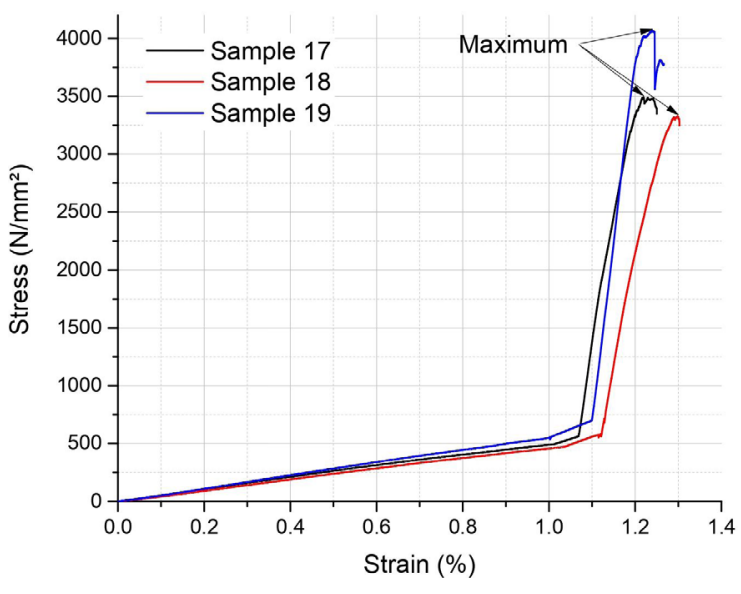




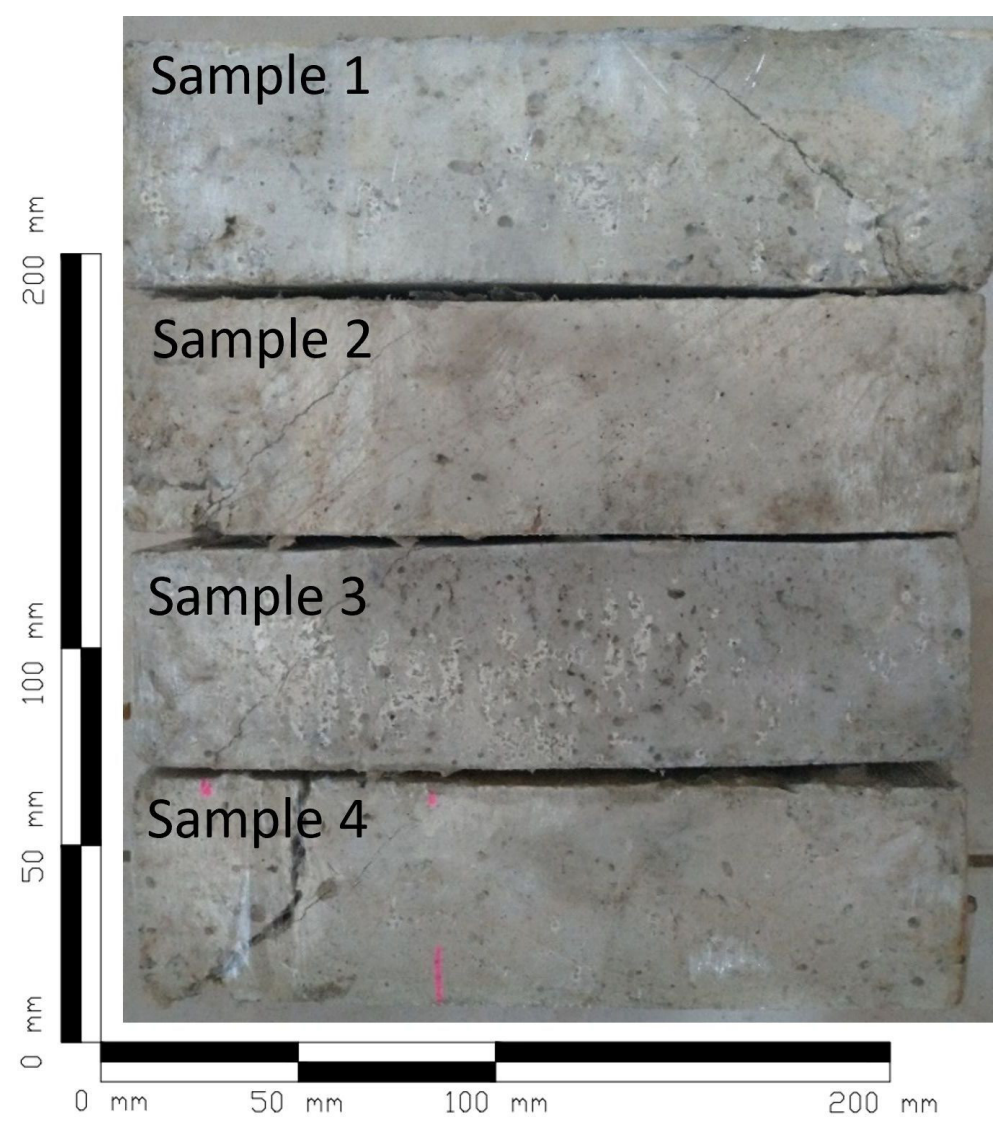

Figure 14. Cracking propagation behavior of reinforced concrete beams (Samples 1 to 4).

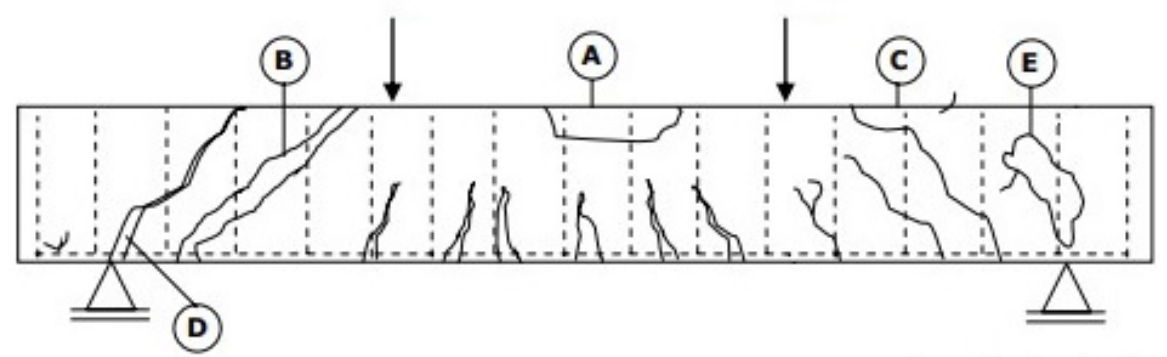

Figure 15. Possible fracture modes in the 4-points bending test ${ }^{43}$.

the beams to withstand bending stresses with the addition of the FRP reinforcement.

However, specimens 10 and 12 showed the same fracture behavior as those without the application of reinforcement. Thus, the fractures occurred with greater load values than in systems without reinforcements, but these specimens continued to fail by shear stress, which may also indicate that this system of reinforcement for bending, also increases the capacity of the beam to support the shear stress that appears, an observed fact that was not essentially expected, confirming the efficiency of the reinforcement system with glass fiber/epoxy resin composites.
Calculating the average values for the second stage, 11,268.2 $\mathrm{N}$ for specimens without composite reinforcement and 27,789.3 $\mathrm{N}$ with the FRP-C reinforcement, the increase in load capacity is again noteworthy, the carbon fiber/epoxy laminate provided a $146.62 \%$ increase in strength.

The same behavior observed in specimens 10 and 12, can also be noticed in specimens 20 to 23 , since all of them fractured due to deficient anchoring of the main reinforcement or due to deficiency of the transversal reinforcement, as occurred in most of the beams without composite reinforcement on this stage. However, with the increase in loading without changing the rupture behavior, it is considered that the composite 


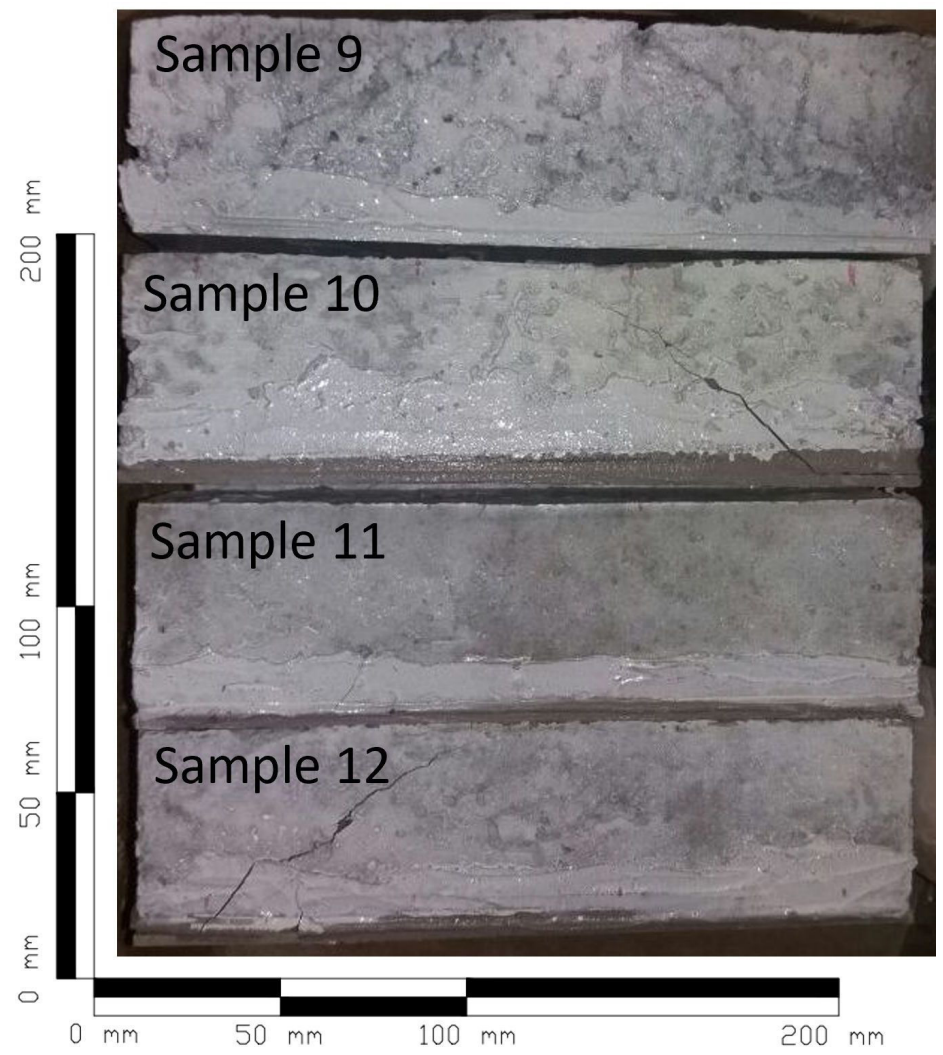

Figure 16. Cracking propagation behavior of FRP-G hybrid beams (Samples 9 to 12).

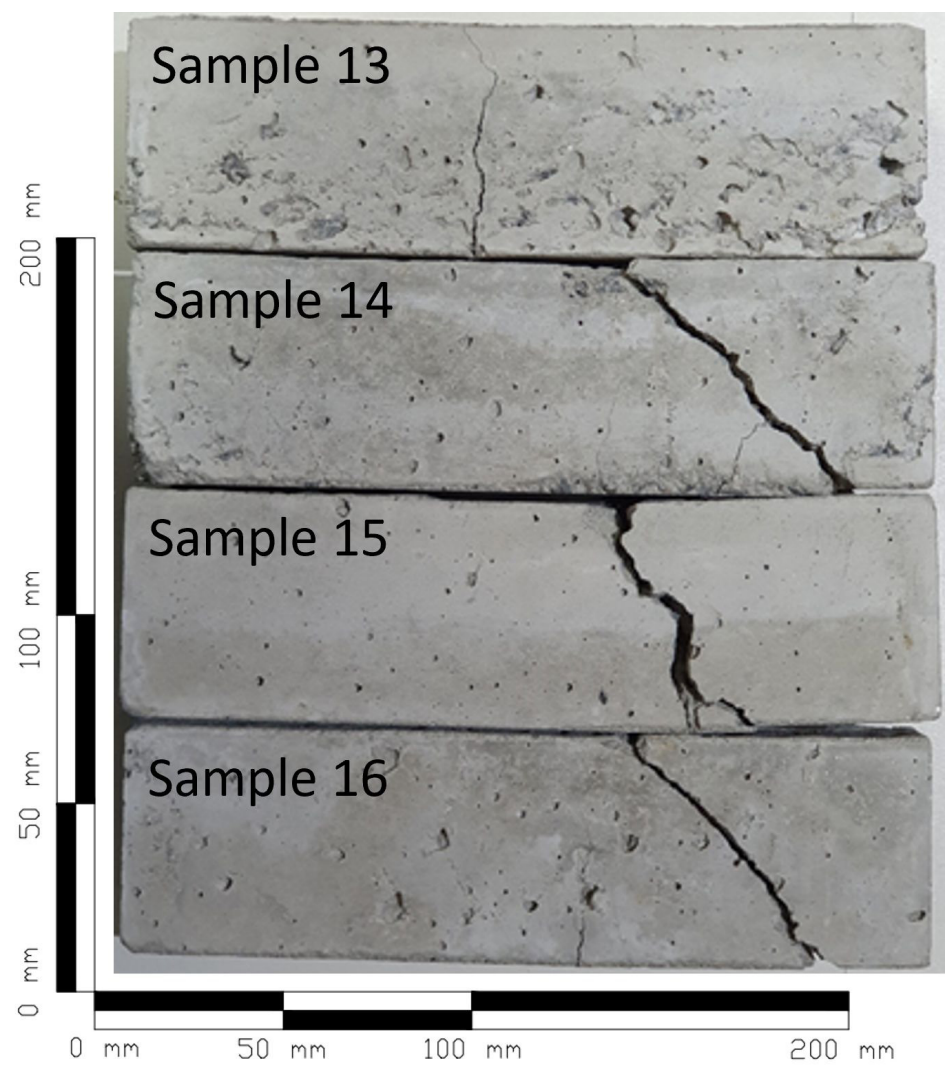

Figure 17. Cracking propagation behavior of reinforced concrete beams (Samples 13 to 16). 


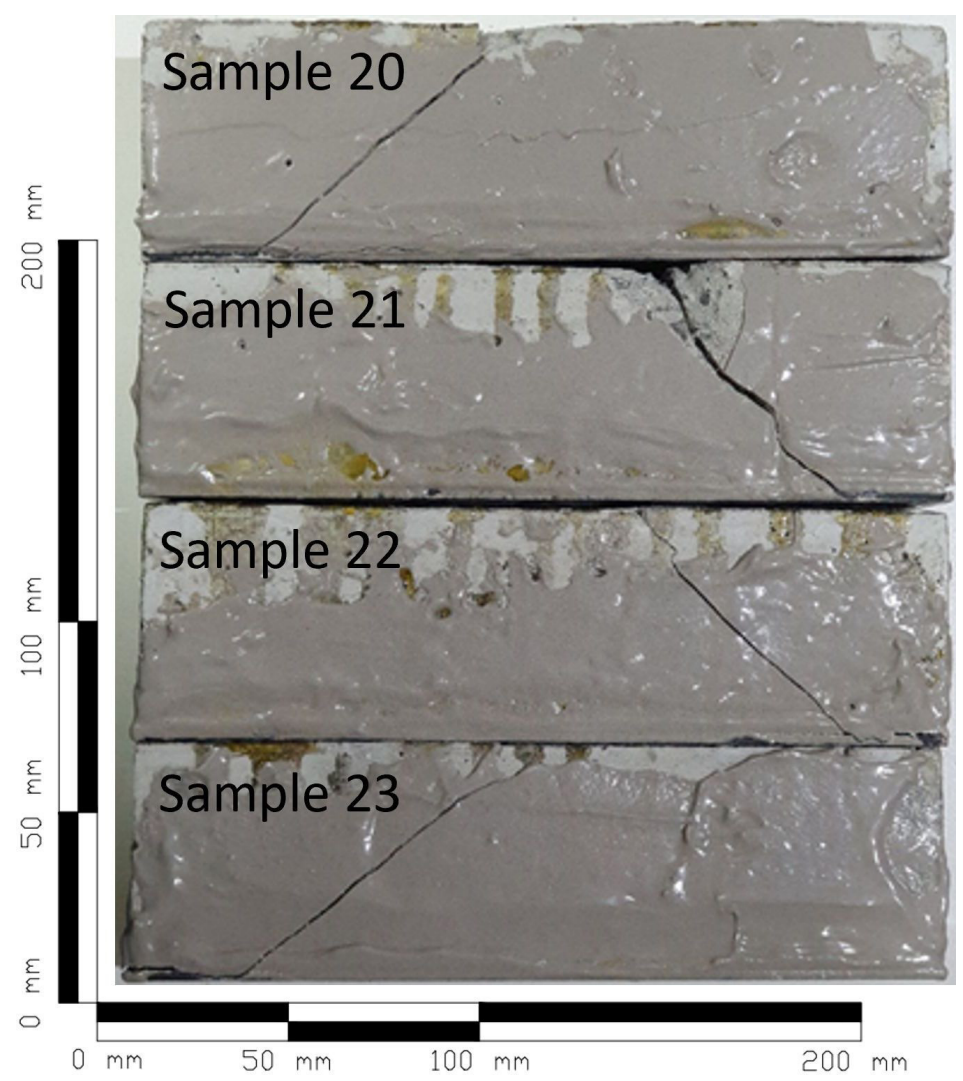

Figure 18. Cracking propagation behavior of FRP-C hybrid beams (Samples 20 to 23).

also contributed to mitigate the effect of these deficiencies, increasing the ultimate load capacity of the beams.

\subsection{Load capacity comparisons between reinforcement systems}

It is also possible to compare the reinforcement systems and how the difference between the mechanical characteristics was transmitted to the reinforcement system. The FRP-G composite showed an average maximum strength of $706.82 \mathrm{~N} / \mathrm{mm}^{2}$, while the FRP-C composite showed an average maximum strength of $3,628.80 \mathrm{~N} / \mathrm{mm}^{2}$, which represents a difference of $413.40 \%$. Carbon fiber is universally recognized for its strength, and such a significant difference was already expected.

However, the hybrid beams with FRP-G had an average maximum strength of $14.9 \mathrm{~N} / \mathrm{mm}^{2}$, while the hybrid beams with FRP-C had an average maximum strength of $19,7 \mathrm{~N} / \mathrm{mm}^{2}$, which represents a percentage increase of $32.2 \%$, a value much lower than that found when comparing composites.

This happens due to several reasons, among them is the fact that the properties of the concrete have not been altered, that is, despite the addition of a tensile reinforcement, the component subject to compression has not been altered. Another possible reason is the interface between the materials, as it was possible to notice, in all FRP-C hybrid beams there was the detachment of the plate, with no apparent damage to the plate itself, indicating that the main reason for the failure was due to the structural adhesive not supporting the transmission of the load, nevertheless, the gain obtained was very expressive, and demonstrates the validity of the reinforcement system.

\section{Conclusion}

This work addresses the use of glass and carbon fibers-based composites with epoxy resin as a structural reinforcement for reinforced concrete beams. Beginning with the appropriate dimensioning of the beams and the composite, the lamination and manufacture of the composite, the preparation of specimens, and the fixation of the composite in them, the structural gain provided by the reinforcement was evaluated.

The results obtained showed a substantial increase in the load capacity of reinforced concrete structures after using the reinforcement system based on FRP. On average, reinforced concrete beams without reinforcement supported a load of approximately $9.7 \mathrm{kN}$ and $11.3 \mathrm{kN}$, while reinforced concrete beams reinforced with the glass fiber composite supported an average of $21.0 \mathrm{kN}$, equivalent to a percentage increase of $116.6 \%$, and concrete beams with carbon fiber composite supported $27.8 \mathrm{kN}$, showing a $146.6 \%$ increase. Comparing the systems, the carbon fiber reinforcement system showed a percentage increase of $32.2 \%$ in comparison with the glass fiber reinforcement system.

The importance of the interface in the success of the reinforcement system of this work is emphasized, the care in this stage is shown as a differential to guarantee the greater 
integration between the concrete substrate and the composite reinforcement. Another factor to be highlighted is the curing cycle determined for the hot compression molding process of the composite, being decisive in maximum consolidation and better structural performance of the composite.

Thus, the studied system proved to be efficient as reinforcement in reinforced concrete beams, offering a considerable increase in strength, as well as validating the calculation and design methods.

\section{Acknowledgments}

The authors acknowledge the financial support received from FAPESP (under grants 2017/16970-0) and CNPq (under grants 303224/2016-9). Also, the authors are indebted to the Brazilian Viapol Company for the material supplied.

\section{References}

1. Frangopol DM, Saydam D, Kim S. Maintenance, management, life-cycle design and performance of structures and infrastructures: a brief review. Struct Infrastruct Eng. 2011;8(1):1-25.

2. Ellingwood BR, Lee JY. Life cycle performance goals for civil infrastructure: intergenerational risk-informed decision. Struct Infrastruct Eng. 2015;12(7):822-9.

3. Subhi M, Dinesh S, Resmi R. A review on construction defects. International Journal of Informative \& Futuristic Research. 2017;4:7079-84.

4. Garrido Vazquez E, Naked Haddad A, Linhares Qualharini E, Amaral Alves L, Amorim Féo I. Pathologies in reinforced concrete structures, sustainable construction. Building Pathology and Rehabilitation. 2016;8:213-28.

5. Lauzin X. (2017). Pathology of structures. In Lauzin X, editor. Civil engineering structures according to the eurocodes. New Jersey: John Wiley \& Sons. p. 95-160.

6. Ravikumar CS, Thandavamoorthy TS. Application of FRP for strengthening and retrofitting of civil engineering structures. Int J Civ Struct Environ Infrastruct Eng Res Dev. 2014;4:49-60.

7. Valluzzi MR, Modena C, Felice G. Current practice and open issues in strengthening historical buildings with composites. Mater Struct. 2014;47(12):1971-85.

8. Tang SW, Yao Y, Andrade C, Li ZJ. Recent durability studies on concrete structure. Cement Concr Res. 2015;78:143-54.

9. Sosdean C, Marsavina L, De Schutter G. Damage of reinforced concrete structures due to steel corrosion. Adv Mat Res. 2015;1111:187-92.

10. Alhadid MMA, Youssef MA. Analysis of reinforced concrete beams strengthened using concrete jackets. Eng Struct. 2017;132:172-87.

11. Gholampour A, Hassanli R, Mills JE, Vincent T, Kunieda M. Experimental investigation of the performance of concrete columns strengthened with fiber reinforced concrete jacket. Constr Build Mater. 2019;194:51-61.

12. Belal MF, Mohamed HM, Morad SA. Behaviour of reinforced concrete columns strengthened by steel jacket. HBRC Journal. 2015;11(2):201-12.

13. Rasheed HA, Abdalla J, Hawileh R, Al-Tamimi AK. Flexural behavior of reinforced concrete beams strengthened with externally bonded Aluminum Alloy plates. Eng Struct. 2017;147:473-85.

14. Hadi MNS, Sarhan MM, Teh LH. Behavior of concrete beams reinforced with steel plates. Struct J. 2018;115(5):1307-15.

15. Spadea G, Bencardino F, Sorrenti F, Swamy RN. Structural effectiveness of FRP materials in strengthening RC beams. Eng Struct. 2015;99:631-41.
16. Gonzalez-Libreros JH, Sneed LH, D’Antino T, Pellegrino C. Behavior of RC beams strengthened in shear with FRP and FRCM composites. Eng Struct. 2017;150:830-42.

17. Pham TM, Hao H. Review of concrete structure strengthened with FRP against impact loading. Structures. 2016;7:59-70.

18. Botelho EC, Scherbakoff N, Rezende MC, Kawamoto AC, Sciamareli J. Synthesis of polyamide $6 / 6$ by interfacial polycondensation with the simultaneous impregnation of carbon fibers. Macromolecules. 2001;34(10):3367-75.

19. Bakis CE, Bank LC, Brown VL, Cosenza E, Davalos JF, Lesko JJ, et al. Fiber-Reinforced polymer composites for construction: state-of-the-art review. J Compos Constr. 2002;73(2):73-87.

20. Batista NL, Olivier P, Bernhard G, Rezende MC, Botelho EC. Correlation Between degree of crystallinity, morphology and mechanical properties of PPS/carbon fiber laminates. Mater Res. 2015;19:195-201.

21. Zaman A, Gutub SA, Wafa MA. A review on FRP composites applications and durability concerns in the construction sector. J Reinf Plast Compos. 2013;32(24):1966-88.

22. Pendhari SS, Kant T, Desai YM. Application of polymer composites in civil construction: a general review. Compos Struct. 2008;84(2):114-24.

23. Schober K-U, Harte AM, Kliger R, Jockwer R, Xu Q, Chen J-F. FRP reinforcement of timber structures. Constr Build Mater. 2015;97:106-18.

24. Qin R, Zhou A, Lau D. Effect of reinforcement ratio on the flexural performance of hybrid FRP reinforced concrete beams. Compos, Part B Eng. 2017;108:200-9.

25. Zhu H, Cheng S, Gao D, Neaz SM, Li C. Flexural behavior of partially fiber-reinforced high-strength concrete beams reinforced with FRP bars. Constr Build Mater. 2018;161:587-97.

26. Gómez EP, González MN, Hosokawa K, Cobo A. Experimental study of the flexural behavior of timber beams reinforced with different kinds of FRP and metallic fibers. Compos Struct. 2019;213:308-16.

27. Hexcel. HexPly® F155 [Internet]. 2016 [cited 2021 Mar 2]. Available from: https://www.heatcon.com/wp-content/ uploads/2017/09/HCS2403-015_Hexcel-F155-71-TDS_Prepreg. pdf

28. ABNT: Associação Brasileira de Normas Técnicas. ABNT NBR 6118:2014: design of concrete structures: procedure. Rio de Janeiro: ABNT; 2014.

29. Araba AM, Ashour AF. Flexural performance of hybrid GFRPSteel reinforced concrete continuous beams. Compos, Part B Eng. 2018;154:321-36.

30. ACI: American Concrete Institute. ACI 440.2R-17: guide for the design and construction of externally bonded FRP systems for strengthening concrete structures. Farmington Hills, MI: ACI; 2017.

31. ACI: American Concrete Institute. ACI 318-19: building code requirements for structural concrete. Farmington Hills, MI: ACI; 2019

32. ABNT: Associação Brasileira de Normas Técnicas. NBR 5739:2007: concrete: compression test of cylindric specimens: method of test. Rio de Janeiro: ABNT; 2007.

33. ASTM: American Society for Testing and Materials. ASTM E2041-13: standard test method for estimating kinetic parameters by differential scanning calorimeter using the borchardt and daniels method. West Conshohocken, PA: ASTM; 2013.

34. ASTM: American Society for Testing and Materials. ASTM E2550-11: standard test method for thermal stability by thermogravimetry. West Conshohocken, PA: ASTM; 2011.

35. Lecomte-Grosbras P, Paluch B, Brieu M. Characterization of free edge effects: influence of mechanical properties, microstructure and structure effects. J Compos Mater. 2012;47(22):2823-34.

36. Koc M, Sonmez FO, Ersoy N, Cinar K. Failure behavior of composites laminates under four-point bending. J Compos Mater. 2016;50(26):3679-97. 
37. Iovinella I, Prota A, Mazzotti C. Influence of surface roughness on the bond of FRP laminates to concrete. Constr Build Mater. 2013;40:533-42.

38. Cabral-Fonseca S, Correia JR, Custódio J, Silva HM, Machado AM, Sousa J. Durability of FRP: concrete bonded joints in structural rehabilitation: a review. Int J Adhes Adhes. 2018;83:153-67.

39. ABNT: Associação Brasileira de Normas Técnicas. ABNT NBR 12142:2010: concrete: determination of tension strength in flexure of prismatic specimens. Rio de Janeiro: ABNT; 2010.

40. Naresh K, Krishnapillai S, Velmurugan R. Effect of fiber orientation on carbon/epoxy and glass/epoxy composites subjected to shear and bending. Diffus Defect Data Solid State Data Pt B Solid State Phenom. 2017;267:103-8.
41. Dong C, Davies IJ. Flexural strength of bidirectional hybrid epoxy composites reinforced by $\mathrm{E}$ glass and T700S carbon fibres. Compos, Part B Eng. 2015;72:65-75.

42. Jefferson AJ, Arumugam V, Dhakal HN. Overview of different damage and common repair methods in composite laminates. In: Jefferson AJ, Arumugam V, Dhakal HN, editors. Repair of polymer composites: methodology, techniques and challenges. United Kingdom: Woodhead Publishing; 2018. p. 45-95.

43. Rocha AC, Oliveira MGD, Resende PSO, Chaer AV. Ensaios de Stuttgart: reprodução em laboratório. In: $46^{\circ}$ Congresso Brasileiro do Concreto; 2004; Florianópolis. Anais. São Paulo: Instituto Brasileiro do Concreto; 2004. 